\title{
Diensthabende
}

\section{Heute ein König}

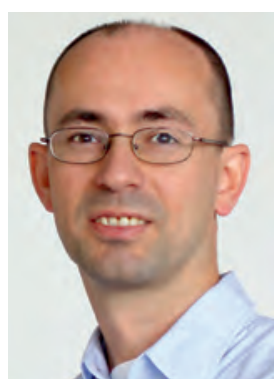

Internisten sehen in ihrem Fach ja gerne die „Königsdisziplin“. Ist das hochnäsig - oder angemessen? In dieser Ausgabe widmen wir uns im Facharztcheck der Inneren Medizin (S. 24). Unsere Autorin hat bei ihren Recherchen mit angehenden Internisten gesprochen. Hochnäsigkeit konnte sie bei keinem entdecken - im Gegenteil: Die jungen Kollegen kannten genau ihre Grenzen und zeigten großen Respekt angesichts dieses riesigen Fachs. Zu Recht denn immerhin sind allein schon die neun internistischen Schwerpunktgebiete für sich genommen größer als mancher Facharzt. Und unter den Krankheitsbildern, die Internisten behandeln, finden sich „Klöpse“ wie die Herzinsuffizienz, an der in Europa 28 Millionen Menschen leiden. Wegen dieser beeindruckenden Breite und Relevanz trägt das Fach seine Krone wahrscheinlich verdient. Ein „König“ in seinem Fach kann aber jeder sein - denn ob man ein guter oder schlechter Arzt ist, hängt nur zu einem kleinen Teil von dem Detailwissen ab, das man sich während des Studiums erwirbt. Auf S. 29 findet ihr unseren Test „Werde ich ein guter Arzt?“ Er vermittelt, worauf es in der Medizin wirklich ankommt! Herzlichst, euer Dieter Schmid www.thieme.de/viamedici

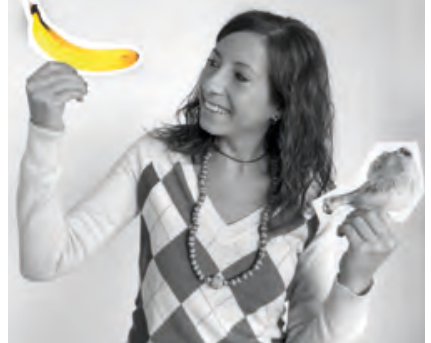

Stephanie Beil

hat Ernährungswissenschaften studiert und erschien uns deshalb als ideale Expertin für einen „evidenzbasierten“ Artikel über Lebensmittelskandale. Trotz der ekligen Details, mit denen sie bei der Recherche konfrontiert wurde, ist ihr der Spaß am Essen zum Glück nicht vergangen (Seite 46).

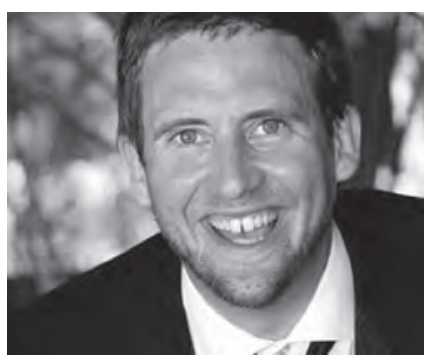

Dr. Lars Lomberg

ist begeisterter Notarzt und arbeitet seit Jahren in großen deutschen Notaufnahmen. In seinem Artikel über den Umgang mit Bewusstseinsstörungen erklärt er, warum es in der Notfallmedizin so wichtig ist, interdisziplinär zu denken und nicht an traditionellen Fachgrenzen haltzumachen (Seite 42).

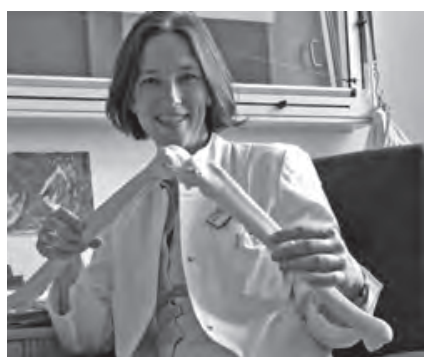

Dr. Yvonne Kollrack hat beim Sportmedizinkurs den ersten Platz im Schießen belegt. Verletzt hat sie dabei zum Glück niemanden. Trotzdem weiß die Unfallchirurgin, wie Schuss- und Stichverletzungen lege artis versorgt werden, und erklärt uns das in diesem Heft (Seite 32). 